\title{
Increasing proportion of Herpes Simplex Type 1 in first episode anogenital herpes in Australian women and men: A retrospective observational study over 13 years
}

\section{Durukan ${ }^{1,2}$ CK Fairley ${ }^{1,2}$ CS Bradshaw 1,2 T Read ${ }^{1,2}$ L Caly $^{3}$ J Druce $^{3}$ M Catton ${ }^{3}$ EP Chow ${ }^{1,2}$}

${ }^{1}$ Melbourne Sexual Health Centre, Alfred Health, Melbourne, Victoria, Australia 2. Central Clinical School, Faculty of Medicine, Nursing and Health Sciences, Monash University, Melbourne, Victoria, Australia 3. Victorian Infectious Diseases Reference Laboratory, 792 Elizabeth Street, Melbourne, 3000, Victoria, Australia

\section{Background}

Globally, anogenital herpes has been predominantly caused by herpes simplex virus type 2 (HSV-2), however since the 1990s there has been an increase in genital HSV-I in developed countries including Australia (I-3) . HSV-I was more prominent in younger people, women and men who have sex with men (MSM) (3). Australian data is over 10 years old and more recent data is needed. In this study we describe the proportions of HSV-I/HSV-2 between 2004 and $20 \mathrm{I}$.in Melbourne, Australia.

\section{Aims}

- To describe recent trends of first episode anogenital herpes by serotype between 2004 and 2017

- To examine the risk factors associated with HSV-I in women, heterosexual men and MSM

\section{Methods}

- 4517 Patients who were diagnosed with first episode genital HSV that was serotyped at MSHC between 2004 and 2017 were included. Serotype was confirmed with TaqMan real time polymerase chain reaction assay.

- Patients were categorised into women, heterosexual men or MSM and analysed by gender and within men by sexual orientation

- We tested the trends in the proportions of HSV-I and HSV-2 for each population using $\mathrm{x}^{2}$ trend test.

- Associations of various risk factors with HSV-I were examined using a logistic regression model.

\section{Results}

\section{Trends of first episode anogenital HSV-I/HSV-2}

The proportion of anogenital herpes due to HSV-I increased by $35 \%$ in women (45\% in 2004 to $61 \% 2017$; $P_{\text {trend }}<0.001$, $\mathrm{N}=1926)$ and $8 \%$ in heterosexual men over 13 years $(38 \%$ in 2004 to $41 \%$ in $2017 ; P_{\text {trend }}=0.01, N=150 I$ )

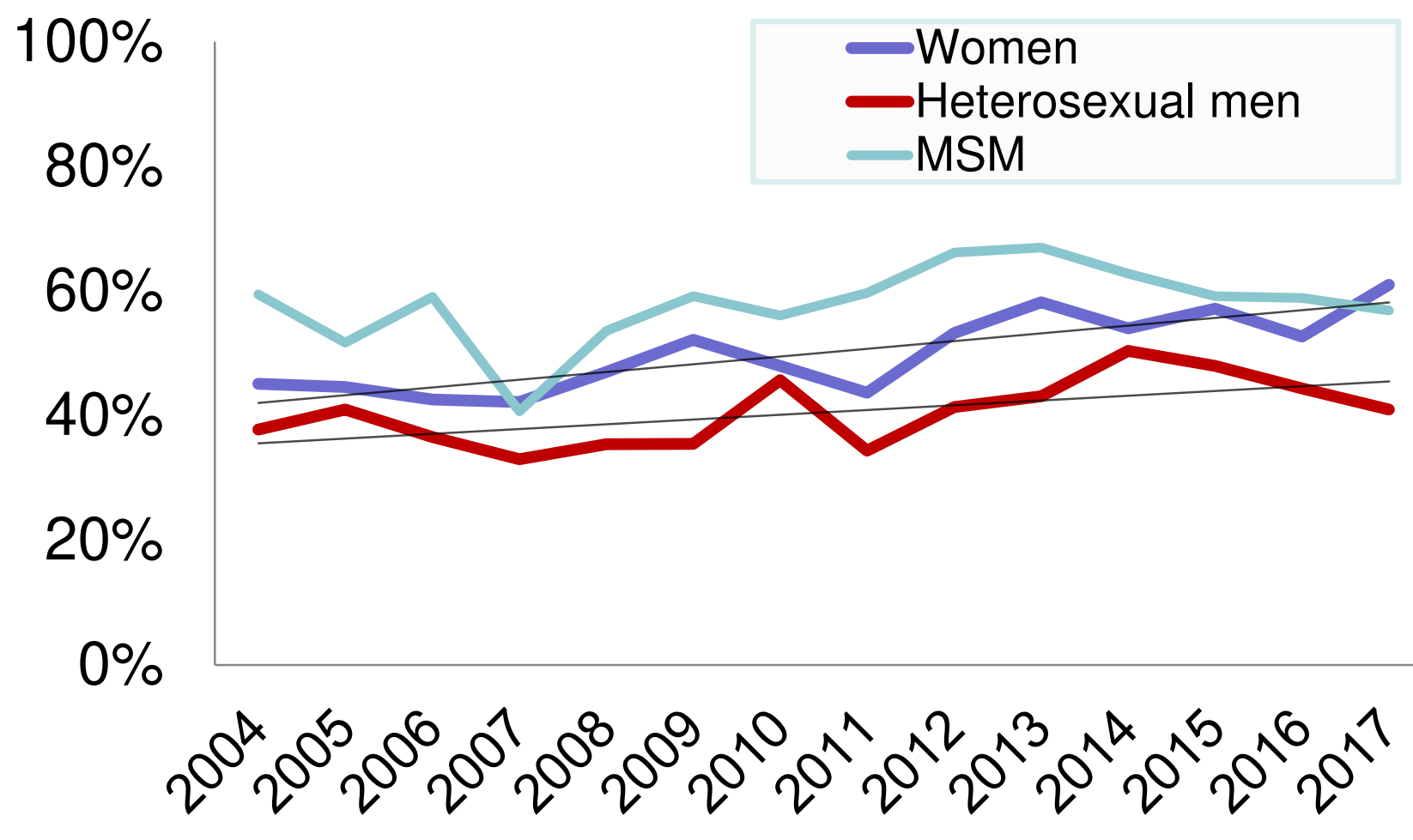

Figure 1: Changes in the proportion of anogenital herpes due to HSV-I between 2004 and 2017
While there was no significant trend in MSM $\left(P_{\text {trend }}=0.21\right.$, $N=1090)$, where site was recorded $(n=689)$, the proportion of first episode anal HSV-I and HSV-2 increased significantly ( $38 \%$ in 2004 to $68 \%$ in $2017, P_{\text {trend }}<0.001, n=4 I I$ ), compared to penile herpes.

Table 1: Multivariate logistic regression of variables predicting the proportion of first episode anogenital HSV-1

\begin{tabular}{|l|l|l|l|l|}
\hline Variable & $\begin{array}{l}\text { Crude OR } \\
(95 \% \mathrm{Cl})\end{array}$ & $\mathbf{p ~ V a l u e}$ & $\begin{array}{l}\text { Adjusted OR } \\
(95 \% \mathrm{Cl})\end{array}$ & $\mathbf{p ~ V a l u e}$ \\
\hline Year of diagnosis & $1.09(1.06-1.13)$ & $<0.001$ & $1.07(1.03-1.10)$ & 0.001 \\
\hline Age & 1 & $<0.001$ & 1 & \\
\hline$\geq 28$ & $2.25(2.00-2.54)$ & $<0.001$ & $2.24(1.98-2.54)$ & $<0.001$ \\
\hline$<28$ & 1 & & 1 & \\
\hline Sexual Orientation & $1.51(1.32-1.73)$ & $<0.001$ & $1.34(1.16-1.55)$ & $<0.001$ \\
\hline Heterosexual men & 1 & & & $<0.001$ \\
\hline Women & $2.04(1.74-2.39)$ & $<0.001$ & $2.18(1.83-2.59)$ & \\
\hline MSM & 1 & & 1 & \\
\hline Condom use & $1(1.00-1.01)$ & 0.03 & $0.83(0.69-1.01)$ & 0.06 \\
\hline Always & 1 & & 1 & \\
\hline Not Always & $1.15(1.00-1.33)$ & 0.05 & $0.99(0.85-1.15)$ & 0.90 \\
\hline Number of Partners & $0.93(0.66-1.31)$ & 0.66 & $0.68(0.47-0.97)$ & 0.04 \\
\hline 1 partner & $0.74(0.52-1.06)$ & 0.10 & $0.53(0.36-0.77)$ & $<0.001$ \\
\hline 2-5 partners & & & & \\
\hline 6-9 partners & 1 & & & \\
\hline 10+ Partners & $1.60(1.32-1.95)$ & $<0.001$ & & \\
\hline Site & & & & \\
\hline Anal & & & & \\
\hline Genital & & & & \\
\hline
\end{tabular}

\section{Conclusion}

- HSV-I is now the main cause of anogenital herpes in Australian women.

- Younger people, MSM and women are more likely to have anogenital HSV-I compared to older people and heterosexual men

- In MSM, increases in anal herpes compared to penile herpes may be due to increasing condomless anal intercourse in this group (4)

. Lowhagen GB, Tunback P, Andersson K, Bergstrom T, Johannisson G. First episodes of genital herpes in a Swedish STD population: a study of epidemiology and transmission by the use of herpes simplex virus (HSV) typing and specific serology. Sex Transm Infect. 2000;76(3):179-82

Ribes JA, Steele AD, Seabolt JP, Baker DJ. Six-year study of the incidence of herpes in genital and nongenital (t) Ryde N, Jn F, MeNuly AM, Grulch AE, Donovan B. Increasing role of herpes simplex virus type I in firstepisode anogenital herpes in heterosexual women and younger men who hav Transm linect. 2009,85(6):416-9

Cex Countries, 1990-2013: A Systematic Review. AIDS Behav. 21, 28II-2834 (2017). 